\title{
The Implementation of Link \& Match Program in Improving Competency Alignment with Business And Industrial World on Vocational Curriculum of Agriculture
}

\author{
Iip Ichsanudin ${ }^{1}$, Ishak Abdulhak ${ }^{1}$, Rusman Hasan ${ }^{1}$, Dadang Sukirman ${ }^{1}$ \\ \{iipichsanudin@gmail.com, ishak.abdulhak@yahoo.com,rusman@upi.edu,dangsukirman@upi.edu\} \\ Universitas Pendidikan Indonesia, Jl. Setiabudhi No. 229 Bandung, Indonesia ${ }^{1}$
}

\begin{abstract}
Various area of expertise is categorized in the spectrum of vocational education expertise. Within the framework of agricultural development, which includes fisheries and livestock, all agree that the existence of a Vocational High School is one of the educational institutions that play an important role in the advancement of agricultural education. Synchronization of the Vocational curriculum according to the needs of graduate users known as Link and Match shows that graduates have a competitive insight or attitude in terms of work ethics, achievement of motivation, mastery, competitiveness, and so on. this program requires a change of mind or a paradigm shift from all stakeholders to ensure relations and adjust program development with the world of work. This condition directs the researcher to ask the question How is the implementation of the link and match program implemented as an effort to improve the suitability of the competencies of the competencies of graduates of vocational schools in Agriculture with the demands of the field of work?.
\end{abstract}

Keywords: link and match, vocational school, the vocational curriculum of agriculture, business and industrial world

\section{Introduction}

The world is facing up the challenge of change which is currently referred to like the challenge of the fourth generation industrial revolution, wherein the fourth industrial revolution era all machines are connected with others, relying on cyber-physical systems that will radically change the way humans live, work, and communicate. The innovation produced to make life more comfortable is not limited, but the challenges that must be solved are also very complex. For this reason, learning in Vocational Schools must develop 21st Century skills to produce graduates who are "innovative, inventive, self-motivated and self-directed, creative problems solvers to confront, more complex global problems" [1]. Meanwhile, Barnet Berry in his monograph entitled The Teachers of 2030: Creating a Student-Centered Profession for the 21st Century, illustrates the dramatic change in the role of educators in the praxis of education in this century. Berry, 2013The perspective that the mission of education is to prepare students to enter certain professions in the type of social roles that have been structured in the community will soon be obsolete. The task of education will turn out to be more important to meet the selfdevelopment needs of students in creating their profession[2][3]. 
Ministry of Education and Culture through the Directorate of Vocational Middle School Development provides reviews and views and facts about the current state of vocational schools in Indonesia. Where the condition of vocational secondary education in Indonesia currently leads to efforts to create graduate human resources for vocational schools that have the capacity of knowledge and knowledge and competencies that are adequate and in accordance with the demands of the times and balanced by the ability to manage emotional and spiritual intelligence that is capable. Based on this, at least there are 2 factors that influence and are categorized as challenges, namely factors or also called internal and external challenges. Internal challenges, among others, related to the condition of education are associated with the demands of education which refers to 8 National Education Standards which include content standards, process standards, graduate competency standards, standards of educators and education personnel, facilities and infrastructure standards, management standards, financing standards, and education assessment standards. Then, other internal challenges related to the development of the Indonesian population are seen from the growth of the productive age population. Currently, Indonesia's population is of productive age (15-64 years) more than unproductive age (children aged 0-14 years and parents aged 65 years and over). The population of productive age will reach its peak in 2020-2035 when the figure reaches $70 \%$. Therefore, the big challenge faced is how to strive so that this abundant productive age human resource can be transformed into human resources that have competence and skills through education so as not to become a burden.

As one of the countries that still holds the title of an agrarian country, we all know that with the blessing of abundant natural wealth, especially agricultural wealth, Indonesia naturally raises this field to become one of the important subjects in sustaining the country's sustainable development. In the framework of agricultural development, which also includes fisheries and livestock, all components agree that the existence of Vocational Schools as an educational institution plays an important role for the advancement of agricultural education itself and develops agricultural innovations and gives birth further skilled workers in their fields. In general, the purpose of the existence of vocational education institutions in agriculture, fisheries, and animal husbandry is to change the behavior of principals and graduates to become competent so that they are able to develop strong agricultural businesses, better farming, better business, live better (better living) and the better environment. Which of course is ultimately based on these qualifications, it is expected that graduates of vocational schools in agriculture are able to work according to the expertise and competencies required by business and industrial world.

Vocational practitioners in the field of expertise in agribusiness and agrotechnology, especially in the fields of agriculture, fisheries, and livestock are required to be able to move the community, empower fish farmers and fishermen, farmers, agricultural entrepreneurs, and agricultural traders. In addition, also must be able to accompany them to: (1) help analyzing the situations that are being faced and make predictions going forward; (2) help find problems; (3) help obtaining knowledge or information to solve problems; (4) help making decisions, and (5) help calculating the amount of risk for the decisions taken. For vocational education in the field of agriculture, the process of curriculum restructuring with the world of work seems to need to be continuously pursued. Considering the development of technology used in this field has also progressed. For example, in the field of processing agricultural products, there are currently so many processed variants emerging and becoming public consumption. In addition, innovation and technological engineering have made many breakthroughs in order to improve the quality and capacity of agriculture in Indonesia. 
In this regard, the Minister of Education and Culture explicitly instructs to sincronyze the vocational curriculum in accordance with the needs of graduate users, or more commonly known as link and match. 'Link' and 'Match' suggest that graduates have competitive insights or attitudes in terms of work ethics, motivation achievement, mastery, and so on. This focus and orientation, of course, requires a change in thinking from all stakeholders in an effort to ensure proactively the development of link and match programs with the world of work. Furthermore, through the Vocational Revitalization program, the implementation of the link and match program is expected to be able to be solutive so as to create a generation of productive age people who are ready for work who have ready-to-use skills or expertise competencies needed by the company and industry. Considering that companies and industries are in desperate need of skilled workers who are ready to work characterized by work ethic and discipline and have high competitiveness. The objectives to be achieved with the existence of this vocational revitalization are: (1) Applying school links and matches with the business or industrial world; (2) Changing the paradigm from push to pull. This means that the vocational paradigm that used to only encourage the creation of graduates without regard to the needs of the labor market changes into a paradigm of looking for everything related to the labor market starting from the work culture and competencies needed in the labor market and attracting them into vocational schools to compile a vocational curriculum aligned with industrial curriculum; (3) Change learning from supply driven to demand driven.; (4) Preparing vocational school graduates who are adaptable to changes in the world to become graduates who can work, continue, and entrepreneurship; (5) Reducing or eliminating the gap between vocational education and DU/DI needs both in terms of technology, administration, and competence.

The condition as previously unraveled directs researchers to identify research problems by raising the question "How is the implementation of the link and match program implemented as an effort to increase the suitability of the competencies of graduates of Agriculture in the field of Agriculture with real demands?" Specifically and more directed, the focus of the identification of the problem is generalized to the following questions: How is the process of aligning the curriculum of vocational schools in agriculture?; Are existing and applicable curriculum able to accommodate the aspirations and suitability of the demands of the working world?; How is the implementation and strategy of curriculum implementation resulting from links and matches in learning activities ?; and what is the quality and absorption of graduates who can meet the qualifications and requirements of the business world and industrial world?

\section{Method}

The research was carried out to provide a description of the implementation of Kirkpatrick's Evaluation Model in the link and match program, particularly in dealing with competency appropriateness of graduates in the vocational school. The school was the vocational school in agriculture which qualified into the vocational school revitalization program by the Directorate of Vocational High School Development, Ministry of Education and Culture of the Republic of Indonesia. This was a descriptive qualitative research. Data on the Kirkpatrick's Evaluation Model was screened using various instruments. For the first level in Kirkpatrick's Evaluation Model, the data were obtained using a questionnaire, which had been estimated for reliability using Cronbach's Alpha. On the other hand, data on the learning outcomes in the students were obtained based on the assessment conducted during the learning process. 


\section{Result and Discussion}

\subsection{Link and Match Program}

Increasing the relevance of Vocational with the business world and industrial world is determined through the policy of vocational schools as a medium-level labor provider institution. The policy has implications for the development and establishment of curriculum and learning design. Correspondingly, the goal of the Vocational High School that was set by BSNP in 2006 was to improve intelligence, knowledge, personality, noble character, and independent living skills and to follow further education in accordance with its vocational skills. Efforts to produce vocational school graduates that are in accordance with the demands of the workforce, need to be supported by a curriculum that is designed and developed with regard to the needs of the workforce. Through the curriculum support, it is expected that vocational's can produce graduates who are able to work as middle-level workers and have the readiness to face job competition by having certain job skills qualifications in accordance with their expertise. The vocational curriculum has a character that leads to the formation of graduate competencies related to the implementation of certain work tasks, and the core vocational competency is found in the production program curriculum based on the scientific basis on adaptive programs, and values in normative programs.

The National Education Policy for Vocational Education in Indonesia in the next decade according to Supriadi (2002: 117), is "with regard to increase relevance, namely the relevance of educational outcomes to the needs of the business world and the industrial world; and the needs and challenges of current and future skills. The policy is known as Link and Match. This policy is basically a means to build partnerships between vocational schools and industry in determining priorities and form forms and materials of vocational training programs".,[4] This pattern is expected in the planning and implementation of education and training programs in vocational schools to pay attention to the tendency of the job market signal and always focus on quality.

The concept of Link and Match between education and industry is ideal, there is a reciprocal relationship to do, there will be a link between labor suppliers and their users. The existence of this reciprocal relationship makes Vocational Schools able to compile a curriculum in accordance with the needs of the workforce. Running a link and match is not a simple thing. Because of that, ideally, there are three components that must move simultaneously to make the link and match program successful, namely vocational school, work world, and government. Of the three components, the role of the vocational school is a must and the most important requirement. Creativity and intelligence of vocational school managers is a determining factor for the success or failure of the program. There are several important steps that must be done by Vocational Schools to make the link and match program successful. Vocational schools must be willing to do research into the world of work. The aim is to find out what competencies are most needed in the workforce and what competencies are most needed in the workforce. In addition, Vocational Schools must also be able to predict and anticipate what skills are needed in the world of work and technology in the next ten years. If the link and match program runs well, the government also benefits from reduced unemployment. Therefore, the government should seriously safeguard the climate of linkages and mechanisms for implementing knowledge from vocational schools to the world of work so that the link and match program is expected to run better and be able to bring benefits to all parties. A real example of this link and match is a program of cooperation with the business or industry world, industrial class development, the implementation of apprenticeship teachers, field Industrial practice, and the role of vocational schools as industrial relations for other schools. 


\subsection{The nature of the Business and Industrial World}

The business world is a place that is the axis of the movement of everything that is innovative, with different techniques, to produce the welfare of many people led by a creative person called an entrepreneur. In the eyes of the industrial world, most people assume that industry is only a human economic activity that processes raw materials into semi-finished goods or finished materials. Even though the understanding of the industry is very broad, this industrial process includes all human activities in a particular field that is productive and commercial. The word industry comes from the ancient Francis language "industry" which means activity, but the word basically comes from the Latin word "Industria" which means crafts and activities. In a broad sense, the industry is a commercial field that uses work skills and technology to produce a product with the aim of gaining profit. Industrial products are not only in the form of goods but also in the form of services, examples of products in the form of services such as banking, insurance, transportation, freight forwarding services and so on.

\subsection{How to do the implementation of link and match program in improving competency on the vocational curriculum of agriculture}

In terms of creating the connection between school and industry which can be said the integrated process of building up skills and competencies, it needs the similar understanding between the area of the world of work or industry and the vocational schooling concerns. It can be taken for granted if the foundation or the basic visions of business and industrial world of working get connected to the effort of education through curriculum, learning theories, simulations, and another way of gaining skills and competencies provided for the students at a school.

Since the launch of ideas, concepts and policies, the Ministry of Education and Culture [2] writes the definition of Link and Match can be summarized as follows; A link is a situation where education has a functional connection to market needs, both from the concept, wisdom, planning, and implementation of its programs. Whereas Match is a situation where programs are developed, fostered, and implemented in the national education system so that they can produce graduates that are in line with the needs of the business world and industrial world both in terms of quantity, type and quality required by the world of work.

In order for the curriculum that is applied in schools to be in accordance with and appropriate to the industry, there needs to be a flow to harmonize or synchronize the curriculum. This flow will make easier for the implementation at schools and as well as the implementation of the industrial curriculum. The following describes the sequencing sequence between school curriculum and industry [5]

The process starts from the Vocational School identifies the ability of students and infrastructure, while the Business World or Industry identifies the needs of Industrial competencies that are in accordance with Vocational Schools. If this has been done then between Vocational Schools and Business or Industry can harmonize (or synchronize) the prevailing curriculum in Vocational Schools in accordance with existing competencies in the industry. After the industrial curriculum is formed, Vocational Schools begin to apply the industrial curriculum to the learning process in schools. Furthermore, the Business World and Industry can monitor the ongoing curriculum process. Finally, SMK graduates will be produced and established as the human resources whose are ready to work aligned with the needs of industry. The establishment of vocational graduates can be used as an evaluation of the development of the next industrial curriculum. Through the process of evaluation, we are going to be able to understand of such the impact of the link and match program wheres as undergo within the world of vocational education particularly in Indonesia [4][6]. To be more specific the author aims to look up the program in the vocational school of agriculture subject. With this regard of 
evaluation of the program, the tool uses four level of evaluation model by Kirkpatrick, there has the level of Reaction, Learning, Behavior, and Result as the matter of evaluation process (see figure 1) [7][8][9][10].

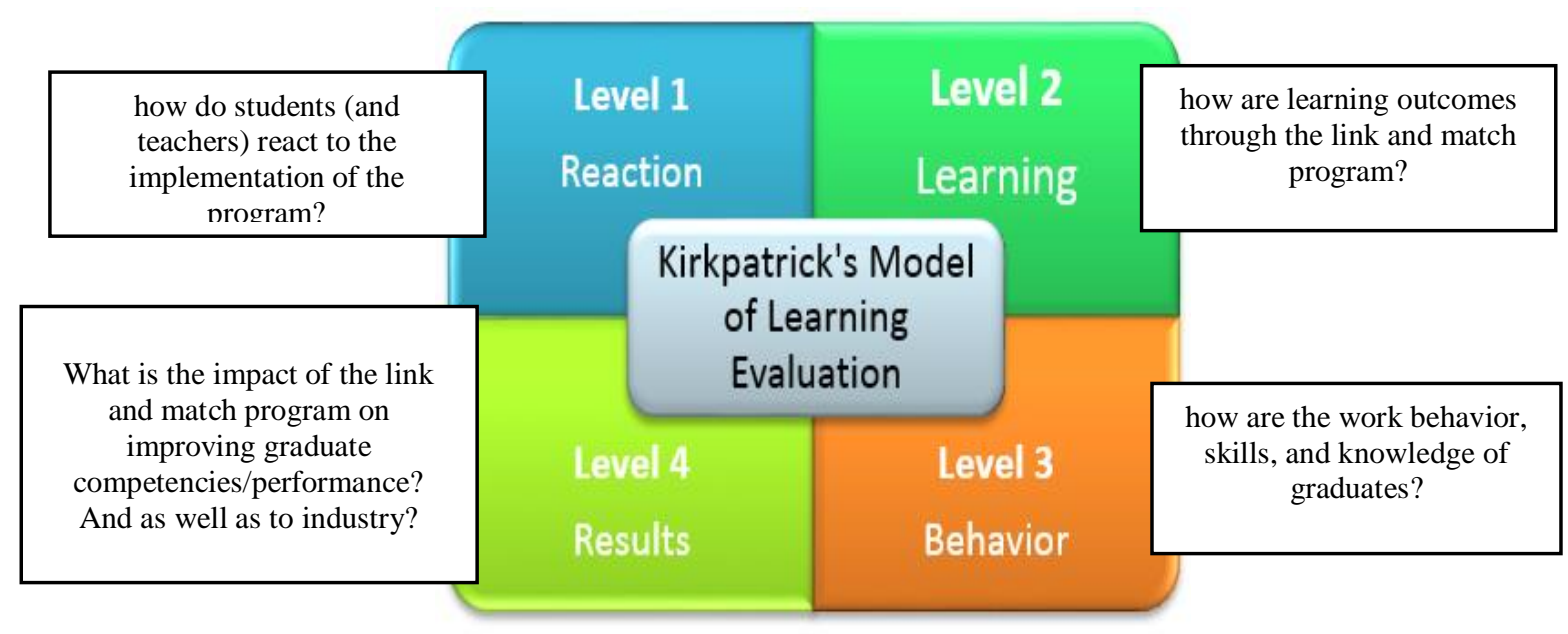

Figure 1. Evaluation Model 4 Stage Kirkpatrck

Kirkpatrick introduces the "four levels" model in conducting training evaluations. Even though, the evaluation method will be applied in the assessment and evaluation of the link and match program conducted by the writer [11][12][13][14]. Those level namely with Level 1 Reaction: this to measure how participants or program respondents react to the implementation of the link and match program; Level 2 - Learning: this to measure how participants or program respondents receive learning activities, whether participants have changed their knowledge, skills, and behavior; Level 3 - Behavior: measuring how the respondents have changed their behavior as a result of the program implementation they involved; and Level 4 - Results: measuring what results were obtained, because the program respondents or trainees participated in training programs, for example, increased productivity and others. While Kirkpatrick reminded that doing level 3 and level 4 evaluations without doing level 1 and level 2 evaluations is a very serious mistake and can produce wrong conclusions. For example: if at the level 3 evaluation there was no change in behavior from the training participants, it was concluded that the overall training program was not effective. This conclusion can be accurate or it might be totally inaccurate. There are many factors that can cause a person to change his behavior, and not just because of factors following the program. It could be that the program is very good, but there is no desire to change from the trainees, or there may be desires but do not know how to change, or other factors outside the trainees, for example, there is no atmosphere conducive to change, or no the benefits of making changes.

\section{Level 1 evaluation - Reaction}

Derived from asking the key question of how do students (and teachers) react to the implementation of the program? the research was trying to figure out the perception of the link and match program. One of the scales of the reactions was the satisfaction, particularly form the respondents which are school principal, vice principal, teachers, students, as well as the industrial partners from schools. The satisfaction of the respondents can be assessed from several aspects, such as learning materials, supporting facilities, the delivery strategy of the material used by the teacher or facilitator, the 
availability learning media, the time of the learning process, and the reactions of the program respondents. Conversely, if they are not comfortable with the learning process they are following, they will not be motivated to take part in further learning or training activities. Partner (2009) stated "the interest, attention, and motivation of the participants are critical to the success of any training program, better people learn when they react positively to the learning environment" [15][16]. It was concluded that the success of the learning process was inseparable from the interest, attention, and motivation of the training participants in following the course of learning activities. Students or training participants will learn better when they react positively to the learning environment. Synchronizing curriculum as one of the efforts to revitalize positioning of SMK, particularly Agriculture vocational high school is expected to bring a refreshing movement to turnover the quality as well as the number of students who take agriculture as the subject for their future [17][18].

Based on the research conducted, it has been found that overwhelmingly respondents reacted positively by committing to the program through following every single phase regarding on it. Systematically the link and match program begins with the process of synchronization contains various contexts. One of the main contexts is curriculum which needed to be shared or collaborated between school and industry. This is to respond to the market demands of graduates from vocational agriculture school. So that school and industry are able to know precisely the fundamental needs of graduate competencies align with the graduate standards which have been stipulated on the act of the government number 19 the year 2005 about education national standard.

\section{Level 2 evaluation - Learning}

The programme's outcome was the concern based that the researcher process through this research. The way of evaluation in terms of the learning phase has been conducted by seeking continuously the two-way of learning. learning can be defined as extensions to which participant change attitudes, improving knowledge, and/or increasing skills as a result of attending the program. There are three things that teachers can teach in the implementation of learning programs, namely knowledge, attitudes, and skills. Students or training participants are said to have learned if they had experienced changes in attitude, improved knowledge, and skills improvement. Therefore, to measure the effectiveness of the training program, these three aspects need to be measured. Without a change in attitude, increased knowledge and improvement of skills in students or training participants, the program can be said to be a failure [19][20][7]. Evaluating learning assesses there are those who call learning outcomes. Therefore in the measurement of learning outcomes (learning measurement) means the determination of one or more of the following: 1) knowledge that has been learned, 2) changes in attitude, and 3) skills that have been developed or improved. Measuring learning outcomes is more difficult and time consuming compared to measuring reactions. Measuring the reaction can be done by reaction sheet in the form of a questionnaire so that it is easier and more effective. An assessment of learning outcomes can be done by: "an if practical control group, evaluate knowledge, skills, and attitudes both before and after the program, a test paper to measure knowledge and attitudes, and performance test to measure skills"[9][21]. Thus to assess learning outcomes can be done with a comparison group. In short, the process can also be done by comparing the results of the pretest with posttest, written tests or performance tests.

\section{Level 3 evaluation - Behavior}

The condition of changing behavior was firstly expected by doing this evaluation level. Researcher felt that this level of evaluation criterion would get totally connected to the prior level of learning. However, as a matter of fact, it has uncovered that Evaluation at level 3 (behavior) is different from evaluating attitudes at level 2. Attitude assessment at level 2 
evaluation is focused on attitudinal changes that occur when learning activities are carried out so that they are more internal, while the behavioral assessment is focused on change behavior of training participants after completing learning [17][22]. So that the assessment of behavior is more external. Because the assessed are behavioral changes after participating in learning activities and returning to their environment, this level 3 evaluation can be referred to as an evaluation of the outcomes of training activities. At this stage, it is expected that after attending the training there will be changes in the behavior of participants in doing the work. And also to find out whether new knowledge, skills, and attitudes as a result of the training program are truly utilized and applied in daily work behavior and have a significant effect on improving the performance or competence in their respective work units.

\section{Level 4 evaluation - Results}

This presumably the hardest part to evaluate. Evaluation of results in level 4 is focused on the final result, which occurs because students or training participants have participated in a learning program. Included in the end result category of a learning program include increasing learning outcomes, increasing knowledge, and increasing skills (skills). Some programs have the goal of increasing work morale and building better teamwork. In other words, an evaluation of the impact program (program influence). Not all the effects of a program can be measured and also take a long time. Therefore, level 4 evaluation is more difficult compared to the previous levels. Evaluation of this final result can be done by comparing the control group with the learning participant group, measuring the ability of students or respondent participants before and after participating in learning whether there is an increase or not [22][13][23]. That evaluation at level-4 aims at whether the training program is useful in achieving organizational goals. The final results in the context of evaluation at level 4 include increased production results, customer satisfaction, increased employee morale, and increased corporate profits[12] The final results include increasing production and quality, decreasing prices, increasing sales. The purpose of gathering information at this level is to examine the impact of the program on all level of learning which taking part as the stakeholder of the agriculture vocational school [24].

Although it does not provide tangible results for the company in the short term, it does not mean that the program is not successful. There may be various factors that influence this, and in fact, it can be immediately known about the cause so that it can be corrected as soon as possible. The researcher found that at least there are two parties that are to profit from education: a) the student, who should develop skills useful for the workplace and life in general, and b) the society, which is interested in school graduates who are competent and responsible contributors to local and global communities.

\section{Conclusions}

The Link and Match concept is the concept of the relationship between educational institutions and the world of work, or in other words, Link and Match is the link between labor suppliers and their users. With this linkage, education as a labor supplier can establish relationships with the business or industrial world. Furthermore with this link and match an institution, particularly a vocational school, can collaborate with other parties, especially with companies or industries so that students can intern at the company. With the existence of Link and Match, the vocational school can find out what competence is most needed by the workforce and what competencies are most needed in the workforce. Meanwhile, the learning process is 
created in conditions that stimulate a fully comprehensive communication and interaction, harmonious relationships between educators and students, a conducive atmosphere for innovation, creation, and production so that mastery of gaining competencies that are expected can be achieved well. In order to claim that agriculture vocational high school has been increasingly promoted by implementing the link and match program, the synchronization process, particularly on the curriculum, between school and industry should be made in priority. So that the community paradigm on the agriculture school will apparently shift from the dislike into like, from awful into awesome. At last, the link and match program which had been implemented in the vocational school was the modest program to increase capacity and to promote the quality of school and graduates. Therefore, the maintained application of the program sustainably will bring good efforts to make a vocational school of agriculture goes forward to align with the needs of the world of work or industry.

\section{Acknowledgments}

We thank all the respondents of this research who has helped and supported the implementation of link and match program in improving competency alignment with business and the industrial world on the vocational high school of Agriculture in Indonesia. Overwhelmingly to the supervisors of the researcher who has given the opportunity to make this paper eligible for publishing.

\section{References}

[1] Direktorat Pembinaan SMK, "Revitalisasi Pendidikan Vokasi," p. 53, 2016.

[2] A. N. Hadam, Sampun, Rahayu, Nasti, Ariyadi, "Strategi Implementasi Revitalisasi SMK," Buku Ser. Revital. SMK, 2017.

[3] P. Ananto Kusuma Seta, "Revitalisasi Pendidikan Vokasi, Inpres Nomor 9 Tahun 2016: Revitalisasi SMK.” Jakarta, 2016.

[4] Kementerian Pendidikan dan Kebudayaan, "Inpres Revitalisasi SMK sebagai Perekat Stakeholder 9.300 Smk," Ed. 4 Tahun 2017, pp. 1-70, 2017.

[5] P. Education, “A Guide to Curriculum Development : Purposes , Practices , Procedures,” pp. 111.

[6] P. Kemdikbud, Panduan Sinkronisasi Bidang Keahlian Di SMK Dengan Prioritas Potensi Unggulan Wilayah dan Tenaga Kerja. 2017.

[7] D. L. Kirkpatrick, "Kirkpatrick' S Learning and Training Evaluation Theory Four Levels of Learning Evaluation," Evaluation, pp. 1-9, 2011.

[8] D. L. Kirkpatrick, "implementing kirkpatrick's four levels TU101 Session Objectives: Understanding of 1. Requirements for an effective training program 2. Overview of the Four Levels 3. Guidelines for implementing each level," pp. 1-17.

[9] J. D. Kirkpatrick and W. Kirkpatrick, "Creating a Post-Training Evaluation Plan.," $T+D$, vol. 67, no. 6, pp. 26-28, 2013.

[10] F. Ikramina and A. Gustomo, "Analysis of Training Evaluation Process Using Kirkpatrick' S Training Evaluation Model At Pt. Bank Tabungan Negara,” J. Bus. Manag., vol. 3, no. 1, pp. 102-111, 2014.

[11] Ö. G. ULUM, "Program Evaluation through Kirkpatrick's Framework," Pacific Bus. Rev. Int. J., vol. 8, no. 1, 2015.

[12] L. Praslova, "Adaptation of Kirkpatrick's four level model of training criteria to assessment of learning outcomes and program evaluation in Higher Education," Educ. Assessment, Eval. Account., vol. 22, no. 3, pp. 215-225, 2010. 
[13] Muhammad Maqsood Khalid, "Exploring the link between Kirkpatrick (KP) and context, input, process and product (CIPP) training evaluation models, and its effect on training evaluation in public organizations of Pakistan," African J. Bus. Manag., vol. 6, no. 1, pp. 274-279, 2012.

[14] D. Kirkpatrick, "Kirkpatrick's 4 level model," vol. 13, no. March, 2012.

[15] S. Q. Badu, "The Implementation of Kirkpatrick's Evaluation Model in the Learning of Initial Value and Boundary Condition Problems," Int. J. Learn. Dev., vol. 3, no. 5, p. 74, 2013.

[16] R. Bates, "A critical analysis of evaluation practice: The Kirkpatrick model and the principle of beneficence," Eval. Program Plann., vol. 27, no. 3, pp. 341-347, 2004

[17] P. H. Management, "Beyond Kirkpatrick: an evaluation dilemma," 2008.

[18] H. M. Abdulghani et al., "Research methodology workshops evaluation using the Kirkpatrick's model: Translating theory into practice," Med. Teach., vol. 36, no. SUPPL.1, 2014.

[19] M. D. Bledsoe, "Correlations in Kirkpatrick's training evaluation model," ProQuest Diss. Theses, p. 54-54 p., 1999.

[20] H. A. Diefes-Dux, C. Samant, T. E. Johnson, and D. O'Connor, “Kirkpatrick's level 1 evaluation of the implementation of a computer-aided process design tool in a senior-level engineering course," J. Eng. Educ., vol. 93, no. 4, pp. 321-331, 2004.

[21] Y. T. Lin, S. C. Chen, and H. T. Chuang, "The effect of organizational commitment on employee reactions to educational training: an evaluation using the Kirkpatrick four-level model.," Int. $J$. Manag., vol. 28, no. 3, pp. 926-939, 2011.

[22] S. McLean mcleans@duke.usask.ca and G. Moss, "They'Re Happy, But Did They Make a Difference? Applying Kirkpatrick'S Framework To the Evaluation of a National Leadership Program," Can. J. Progr. Eval., vol. 18, no. 1, pp. 1-23, 2003.

[23] K. A. Naugle, L. B. Naugle, and R. J. Naugle, "Kirkpatrick's evaluation model as a means of evaluating teacher performance," Education, vol. 121, no. 1, pp. 135-144, 2000.

[24] A. Smidt, S. Balandin, J. Sigafoos, and V. A. Reed, "The Kirkpatrick model: A useful tool for evaluating training outcomes," J. Intellect. Dev. Disabil., vol. 34, no. 3, pp. 266-274, 2009. 